\title{
Symbols, abbreviations and writing conventions
}

All the relevant notions and formalisms cannot be explained here; the reader is kindly invited to consult the Glossary (pp. 406ff) and the monograph Mel'čuk 2012-2015.

All interlinear glosses in the examples are literal; two English words that correspond to one foreign form are united by a dot: Rus. boli 'of.pain'.

\section{Symbols}

\begin{tabular}{|c|c|}
\hline C & condition part of a linguistic rule \\
\hline L & a particular language \\
\hline $\mathrm{L}$ & a particular lexical unit \\
\hline , & a particular fictitious lexeme (in the deep-syntactic structure) \\
\hline $\mathrm{L}\left({ }^{\prime} \mathrm{X}\right.$ ') & a particular lexical unit $L$ expressing the meaning ' $\mathrm{X}$ ' \\
\hline$\left.x_{1}, x_{2}, \ldots, x_{n}\right)$ & $\begin{array}{l}\left(x_{1}, x_{2}, \ldots, x_{n}\right) \\
\text { features }\end{array}$ \\
\hline${ }_{1} \ldots \mathrm{L}_{\mathrm{n}}{ }^{\top}$ & a particular idiom $\mathrm{L}_{1} \ldots \mathrm{L}_{\mathrm{n}}$ \\
\hline${ }_{1}-\mathbf{s e m} \rightarrow \mathrm{L}_{2}$ & $\mathrm{~L}_{2}$ directly depends on $\mathrm{L}_{1}$ semantically \\
\hline- synt $\rightarrow \mathrm{L}_{2}$ & $\mathrm{~L}_{2}$ directly depends on $\mathrm{L}_{1}$ syntactically \\
\hline $\mathrm{L}_{1}-\cdots \rightarrow \mathrm{L}_{2}$ & $\mathrm{~L}_{2}$ indirectly depends on $\mathrm{L}_{1}$ \\
\hline $\mathrm{L}_{1} \triangleleft \cdots \cdots \mathrm{L}_{2}$ & $\mathrm{~L}_{1}$ and $\mathrm{L}_{2}$ are co-referential $\left(=\mathrm{L}_{1}\right.$ and $\mathrm{L}_{2}$ have the same referent) \\
\hline & important but tangential (= logically not necessary) information \\
\hline & a particular surface-syntactic dependency relation \\
\hline & Rheme (communicative value) \\
\hline Synt & deep-syntactic Rheme (communicative value) \\
\hline iem & semantic Rheme (communicative value) \\
\hline ‘ $\sigma$ ’ & a particular semanteme \\
\hline ' $\underline{\sigma}$ & $\begin{array}{l}\text { a particular semanteme that is communicatively dominant within } \\
\text { the semanteme configuration it belongs to }\end{array}$ \\
\hline & a particular configuration of semantemes \\
\hline & Theme (communicative value) \\
\hline DSynt & deep-syntactic Theme (communicative value) \\
\hline 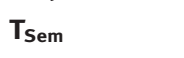 & semantic Theme (communicative value) \\
\hline hey» & $\begin{array}{l}\text { the expression «they» represents the indefinite-personal pronoun, } \\
\text { such as THEY (in the sentence In Yorkshire they say "eh" whenever } \\
\text { they don't understand something), Fr. on, Ger. MAN }\end{array}$ \\
\hline & a set of elements $x_{\mathrm{i}}$ \\
\hline & feature of syntactics of a linguistic sign \\
\hline
\end{tabular}




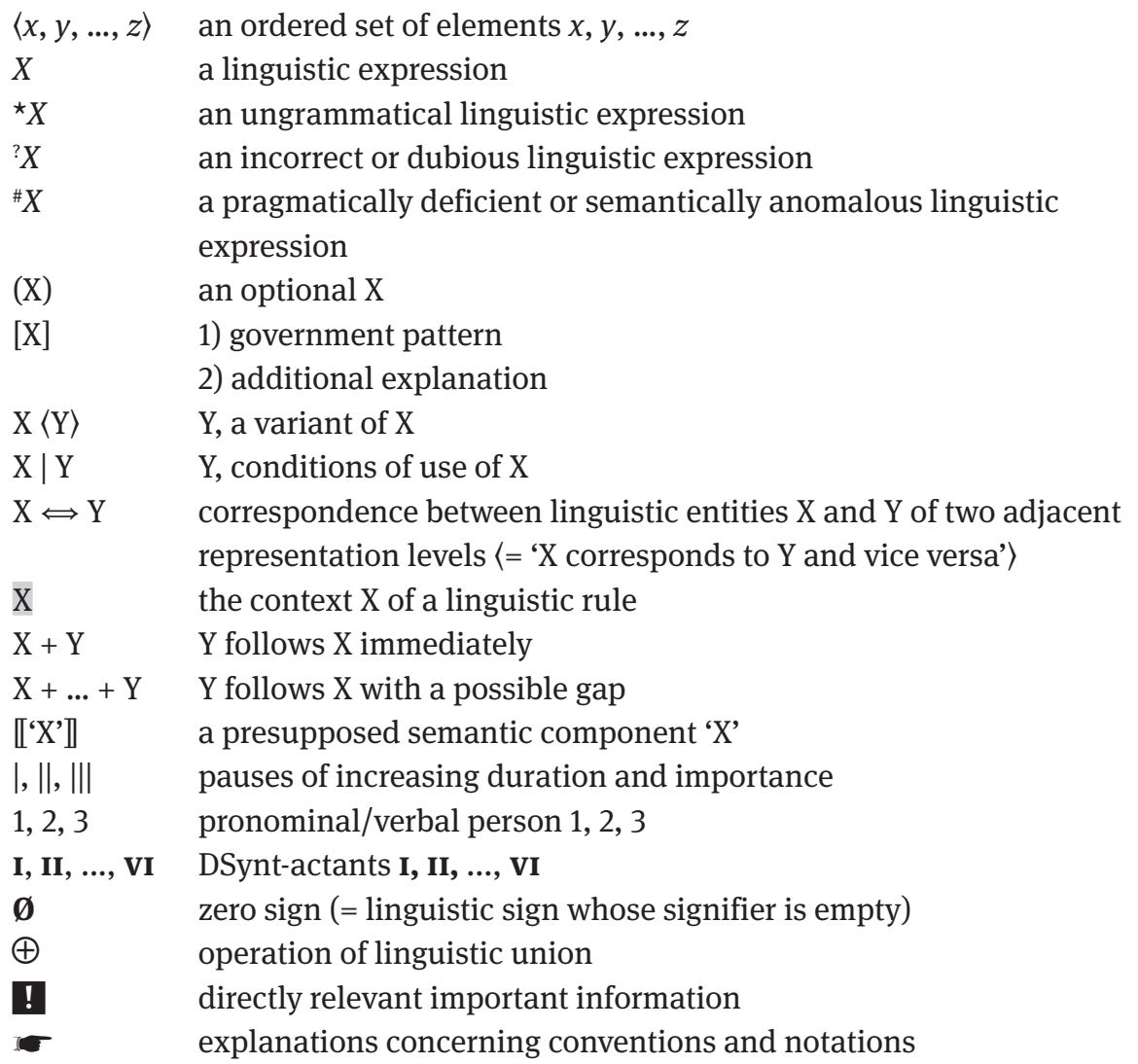

\section{Abbreviations}

$\begin{array}{ll}\text {-A } & \text { actant } \\ \text { A }\langle=\text { ADJ }\rangle & \text { adjective (part of speech) } \\ \text { ACC } & \text { accusative (grammeme of nominal/adjectival case) } \\ \text { ACT } & \text { active (grammeme of verbal voice) } \\ \text { ADV } & \text { adverb (part of speech) } \\ \text { AgCo } & \text { agentive complement (a clause element) } \\ \text { AOR } & \text { aorist (grammeme of verbal tense) } \\ \text { APPEND } & \text { the APPENDITIVE deep-syntactic relation } \\ \text { ART } & \text { article } \\ \text { ATTR } & \text { the ATTRIBUTIVE deep-syntactic relation } \\ \text { CLAUS } & \text { clausative (part of speech) } \\ \text { colloq. } & \text { colloquial (stylistic label) }\end{array}$




\begin{tabular}{|c|c|}
\hline COORD & the COORDINATIVE deep-syntactic relation \\
\hline CONJ & conjunction (part of speech) \\
\hline CONV & converb (grammeme of verbal finiteness: deverbal adverb) \\
\hline $\mathrm{D}$ & (syntactic) dependent \\
\hline D- & deep (sublevel of a linguistic representation) \\
\hline DAT & dative (grammeme of nominal/adjectival case) \\
\hline DECL & declarative (grammeme of verbal mood) \\
\hline DEF & definite (grammeme of nominal determination) \\
\hline DET & determiner (syntactic class of lexemes) \\
\hline DirO & direct object (a clause element) \\
\hline DMorphR & deep-morphological representation \\
\hline DPhonR & deep-phonic (= phonological) representation \\
\hline DSyntA & deep-syntactic actant \\
\hline DSynt-AnaphS & deep-syntactic anaphoric structure \\
\hline DSynt-CommS & deep-syntactic communicative structure \\
\hline DSynt-ProsS & deep-syntactic prosodic structure \\
\hline DSyntR & deep-syntactic representation \\
\hline DSyntRel & deep-syntactic relation \\
\hline DSyntS & deep-syntactic structure \\
\hline ECD & Explanatory Combinatorial Dictionary \\
\hline FEM & feminine (grammeme of adjectival/verbal gender) \\
\hline fem & $\begin{array}{l}\text { feminine (gender; a value of the syntactic feature GENDER of a } \\
\text { noun) }\end{array}$ \\
\hline FUT & future (grammeme of verbal tense) \\
\hline $\mathrm{G}$ & (syntactic) governor \\
\hline GER & gerund (grammeme of verbal finiteness) \\
\hline GP & Government Pattern \\
\hline HON & honorific (grammeme of the category of politeness) \\
\hline iff & if and only if \\
\hline impers & impersonal (value of a syntactic feature of a pronoun) \\
\hline IMPF & imperfective (grammeme of verbal aspect) \\
\hline IND & indicative (grammeme of verbal mood) \\
\hline INF & infinitive (grammeme of verbal finiteness) \\
\hline IndirO & indirect object (a clause element) \\
\hline INDEF & indefinite (grammeme of nominal determination) \\
\hline intrans & intransitive (value of the syntactic feature TRANSITIVITY of a verb) \\
\hline LDOCE & Longman Dictionary of Contemporary English \\
\hline $\mathrm{LF}$ & lexical function \\
\hline LU & lexical unit \\
\hline lit. & literal \\
\hline
\end{tabular}




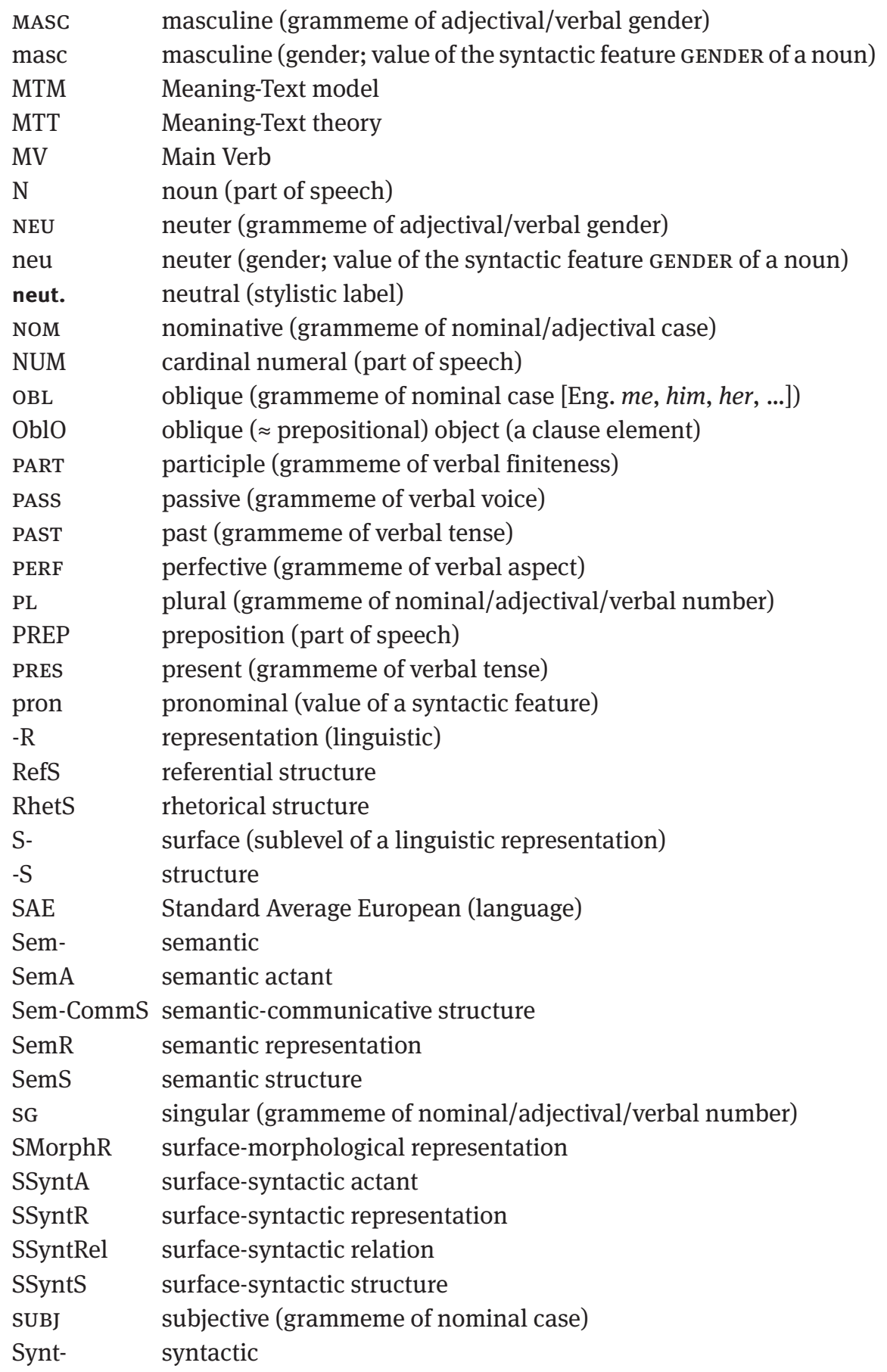


SyntR syntactic representation

SyntSubj syntactic subject (a clause element)

trans transitive (value of the syntactic feature TRANSITIVITY of a verb)

$\mathrm{V} \quad$ verb (part of speech)

$\mathrm{V}_{\text {FIN }} \quad$ finite verb

vulg. $\quad$ vulgar (stylistic label)

\section{Writing conventions}

Linguistic examples are in italics.

Textual glosses are in roman and between 'semantic quotes'.

Lexical units are in SMALL CAPITALS.

$\underline{\text { Grammemes }}\langle=$ inflectional values $\rangle$ are in UPPER CASE: PAST, PL(URAL), etc.

Derivatemes are in HELVETICA ITALICS CAPS: 'ONE WHO [L-s]' (read+er from read L, $^{\text {, }}$ teach+er from teach ${ }_{\mathrm{L}}$.

The names of lexical functions are in Courier New: $\mathrm{S}_{0}$, Magn, Oper ${ }_{1}$, etc.

At their first mention (and sporadically where it is deemed useful), technical terms are in Helvetica in the main text: antonymy, dependency, semanteme, etc. 
